\title{
Prevotella copri sp. nov. and Prevotella stercorea sp. nov., isolated from human faeces
}

\author{
Hidenori Hayashi, ${ }^{1} \dagger$ Kensaku Shibata, ${ }^{1,2}$ Mitsuo Sakamoto, ${ }^{1}$ \\ Shinichi Tomita ${ }^{2}$ and Yoshimi Benno ${ }^{1}$ \\ ${ }^{1}$ Microbe Division/Japan Collection of Microorganisms, RIKEN BioResource Center, 2-1 \\ Hirosawa, Wako, Saitama 351-0198, Japan \\ ${ }^{2}$ Department of Life Science, Faculty of Agriculture, Tamagawa University, \\ 6-1-1 Tamagawa-Gakuen, Machida, Tokyo 194-8610, Japan
}

Correspondence

Hidenori Hayashi

h-hayashi@maebashi-it.ac.jp
Six strains $\left(C B 7^{\top}, C B 18, C B 23, C B 26, C B 28\right.$ and $\left.C B 35^{\top}\right)$ were isolated from human faeces. Based on phylogenetic analysis, phenotypic characteristics, cellular fatty acid profiles and menaquinone profiles, these strains could be included within the genus Prevotella and made up two clusters. 16S rRNA gene sequence analysis indicated that five strains were most closely related to Prevotella veroralis, sharing about $92 \%$ sequence similarity; the remaining strain was most closely related to Prevotella shahii, sharing about $90 \%$ sequence similarity. All six strains were obligately anaerobic, non-pigmented, non-spore-forming, non-motile, Gram-negative rods. The cellular fatty acid compositions of the six strains differed significantly from those of other Prevotella species. Five strains (CB7 ${ }^{\top}, \mathrm{CB} 18, \mathrm{CB} 23, \mathrm{CB} 26$ and CB28) contained dimethyl acetals and the major menaquinones of these strains were MK-11, MK-12 and MK-13. The major menaquinones of $\mathrm{CB} 35^{\top}$ were MK-12 and MK-13. Based on phenotypic and phylogenetic findings, two novel species, Prevotella copri sp. nov. and Prevotella stercorea sp. nov., are proposed, representing the two different strain clusters. The DNA G $+C$ contents of strains $C B 7^{\top}$ and $C B 35^{\top}$ were 45.3 and 48.2 mol\%, respectively. The type strains of $P$. copri and $P$. stercorea are $\mathrm{CB}^{\top}$ $\left(=\mathrm{JCM} 13464^{\top}=\mathrm{DSM} 18205^{\top}\right)$ and $\mathrm{CB} 35^{\top}\left(=\mathrm{JCM} 13469^{\top}=\mathrm{DSM} 18206^{\top}\right)$, respectively.
The application of molecular biological techniques has enabled phylogenetic analysis of bacterial 16S rRNA genes in the human gut. In particular, phylogenetic analysis based on $16 \mathrm{~S}$ rRNA genes has made it possible to clarify the dominant human faecal microbiota (Eckburg et al., 2005; Hold et al., 2002; Suau et al., 1999; Wilson \& Blitchington, 1996; Zoetendal et al., 1998). A large number of species that have not yet been identified and characterized exists in the human gut. It has been reported that the human faecal microbiota could be analysed by $16 \mathrm{~S}$ rRNA gene libraries and strictly anaerobic culture-based methods (Hayashi et al., 2002a, b). Many novel operational taxonomic units (OTUs) and isolates that have not yet been characterized were detected and

tPresent address: Faculty of Engineering, Maebashi Institute of Technology, 460-1 Kamisatori, Maebashi, Gunma 371-0816, Japan.

Abbreviation: OTU, operational taxonomic unit.

The GenBank/EMBL/DDBJ accession numbers for the 16S rRNA gene sequences of $P$. copri $\mathrm{CB}^{\top}$ and $P$. stercorea $\mathrm{CB}^{\top} 5^{\top}$ are AB064923 and AB244774, respectively.

API 20A test results, cellular fatty acid compositions, menaquinone compositions and API ZYM and API An-Ident test results of P. coprisp. nov., $P$. stercorea sp. nov. and related species are available as supplementary material in IJSEM Online. phylogenetic correlation between novel isolated strains and 16S rRNA sequences has been shown. Some novel OTUs and isolates were phylogenetically related to the genus Prevotella. These isolates were the predominant species in human faeces. Suau et al. (1999) and Eckburg et al. (2005) also detected some novel OTUs belonging to the genus Prevotella from 16S rRNA gene library data. Although Prevotella species have been isolated mainly from the oral cavity, these species also inhabit the human gut. Here, two novel species within the genus Prevotella isolated from human faeces are reported.

The strains used in the present study were maintained on Eggerth Gagnon (EG) agar (Merck) supplemented with $5 \%$ $(\mathrm{v} / \mathrm{v})$ horse blood for 2 days at $37^{\circ} \mathrm{C}$, in an atmosphere containing $100 \% \mathrm{CO}_{2}$. Strains $\mathrm{CB}^{\mathrm{T}}, \mathrm{CB} 18, \mathrm{CB} 23, \mathrm{CB} 26$, $\mathrm{CB} 28$ and $\mathrm{CB}^{\mathrm{T}}{ }^{\mathrm{T}}$ were isolated from faeces of a healthy Japanese male (52 years old) using medium 10 and the 'plate-in-bottle' method as described previously (Hayashi et al., 2002a; Mitsuoka et al., 1969). Briefly, after collecting samples, each $0.5 \mathrm{~g}$ faecal sample was immediately suspended in dilution buffer and $50 \mu 10^{8}$-diluted faecal sample was plated anaerobically on medium 10 by using the 'plate-in-bottle' filled with $100 \% \mathrm{CO}_{2}$. Isolates were subcultured on EG agar. Bacteroides bile aesculin agar (Shah, 
1992) was used to check whether growth of the isolates was inhibited on this medium.

Physiological, biochemical and enzyme activity tests were performed by inoculation of API 20A, API ZYM and API An-Ident (bioMérieux) test strips according to the manufacturer's instructions followed by incubation at $37^{\circ} \mathrm{C}$ in anaerobic jars. The isolates were cultured in PYG broth for analysis of metabolic end products (Sakamoto et al., 2004, 2005a). The metabolic end products were prepared as described by Holdeman et al. (1977) and analysed as described previously (Sakamoto et al., 2004, 2005a). Cellular fatty acid profiles were determined using the MIDI Microbial Identification System (Microbial ID). Saponification, methylation, extraction and determination of cellular fatty acid profiles were conducted as described previously (Sakamoto et al., 2002). Isoprenoid quinones were extracted as described by Komagata \& Suzuki (1987) and analysed as described previously (Sakamoto et al., 2004, 2005a). Genomic DNA was extracted from cells harvested from Gifu anaerobic medium (Nissui). Cells were suspended in buffer A (10 mM Tris/HCl and 10 mM EDTA, $\mathrm{pH}$ 8.0) containing Triton X-100 (final concentration, $1.5 \%$ ) and centrifuged at $19000 \mathrm{~g}$ for $5 \mathrm{~min}$. Cells were then resuspended in buffer A containing proteinase $\mathrm{K}$ (final concentration, $2 \mathrm{mg} \mathrm{ml}^{-1}$ ). After incubation at $37^{\circ} \mathrm{C}$ for $10 \mathrm{~min}$, Triton $\mathrm{X}-100$ was added to a final concentration of $1.5 \%$ and the mixture was centrifuged at $19000 \mathrm{~g}$ for $5 \mathrm{~min}$. The following operations were carried out as described previously (Sakka et al., 1989). The G+C content was determined by using the HPLC method (Kitahara et al., 2001; Tamaoka \& Komagata, 1984). The 16S rRNA gene was analysed as described previously (Hayashi et al., 2002a). Sequence data were aligned with the Clustal W package (Thompson et al., 1994) and corrected by manual inspection. Nucleotide substitution rates ( $K_{\text {nuc }}$ values) were calculated and phylogenetic trees were constructed using the neighbour-joining method (Kimura, 1980; Saitou \& Nei, 1987). Bootstrap resampling analysis (Felsenstein, 1985) of 100 replicates was performed to estimate the confidence of tree topologies.

Cells of strains $\mathrm{CB}^{\mathrm{T}}$, CB18, CB23, CB26 and $\mathrm{CB} 28$ were obligately anaerobic, non-spore-forming, non-motile, Gram-negative rods. Cells of these five strains on EG agar were $0.83 \times 0.91-0.99 \mu \mathrm{m}$ in size and occurred singly; colonies were $0.3-2.0 \mathrm{~mm}$ in diameter, milk-white, circular, entire, slightly convex and smooth on EG agar plates. Cells of strain $\mathrm{CB} 35^{\mathrm{T}}$ were obligately anaerobic, non-sporeforming, non-motile, Gram-negative rods. Cells of strain $\mathrm{CB} 35^{\mathrm{T}}$ on EG agar were $0.25-0.42 \times 1.08-1.25 \mu \mathrm{m}$ in size and occurred singly; colonies were $0.2-1.8 \mathrm{~mm}$ in diameter, translucent, circular, entire, slightly convex and smooth on EG agar plates. Physiological and biochemical properties of the six novel strains, Prevotella melaninogenica JCM $6325^{\mathrm{T}}$, Prevotella loescheii JCM $8530^{\mathrm{T}}$, Prevotella marshii JCM $13450^{\mathrm{T}}$, Prevotella oralis JCM $12251^{\mathrm{T}}$, Prevotella salivae JCM $12084^{\mathrm{T}}$, Prevotella shahii JCM $12083^{\mathrm{T}}$ and Prevotella veroralis JCM $6290^{\mathrm{T}}$ were determined by API 20A. Five strains
$\left(\mathrm{CB}^{\mathrm{T}}{ }^{\mathrm{T}}, \mathrm{CB} 18, \mathrm{CB} 23, \mathrm{CB} 26\right.$ and $\left.\mathrm{CB} 28\right)$ could be differentiated from P. melaninogenica JCM $6325^{\mathrm{T}}$, Prevotella oulorum NCTC $11871^{\mathrm{T}}, P$. salivae JCM $12084^{\mathrm{T}}$ and P. veroralis JCM $6290^{\mathrm{T}}$ by D-mannose and L-rhamnose fermentation (see Supplementary Table S1 available in IJSEM Online). Strain $\mathrm{CB} 35^{\mathrm{T}}$ could be differentiated from $P$. loescheii JCM $8530^{\mathrm{T}}$ by gelatin digestion and aesculin hydrolysis, from $P$. marshii JCM $13450^{\mathrm{T}}$ by lactose and sucrose fermentation and gelatin digestion, from $P$. oralis JCM $12251^{\mathrm{T}}$ by aesculin hydrolysis and D-cellobiose and lactose fermentation and from $P$. shahii JCM $12083^{\mathrm{T}}$ by gelatin digestion.

The cellular fatty acid composition of Bacteroides species has been determined (Mayberry et al., 1982; Miyagawa et al., 1979; Shah \& Collins, 1980) and used to provide a classification for members of the genus Bacteroides (Shah \& Collins, 1983). The major cellular fatty acids of strains $\mathrm{CB}^{\mathrm{T}}$, CB18, CB23, СB26 and $\mathrm{CB} 28$ were $\mathrm{C}_{16: 0}, \mathrm{C}_{18: 1} \omega 9 c$ and anteiso- $\mathrm{C}_{15: 0}$. In addition, these strains contained dimethyl acetals. Recently, Prevotella multisaccharivorax has been reported to possess dimethyl acetals (Sakamoto et al., 2005b). The major cellular fatty acids of strain $\mathrm{CB}_{3} 5^{\mathrm{T}}$ were anteiso- $\mathrm{C}_{15: 0}$, iso- $\mathrm{C}_{15: 0}$ and $\mathrm{C}_{18: 1} \omega 9 c$ (see Supplementary Table S2 available in IJSEM Online).

The major menaquinones of strains $\mathrm{CB} 7^{\mathrm{T}}, \mathrm{CB} 18, \mathrm{CB} 23$, CB26 and CB28 were MK-11, MK-12 and MK-13 (see Supplementary Table S3 available in IJSEM Online), whereas the major menaquinones of strain $\mathrm{CB} 35^{\mathrm{T}}$ were MK-12 and MK-13. The major menaquinones of other Prevotella species are generally MK-10 and MK-11 (Sakamoto et al., 2005a).

The API ZYM and API An-Ident systems have been reported to be useful in the identification of oral and non-oral Gramnegative bacteria (Laughon et al., 1982; Slots, 1981; Tanner et al., 1985). The biochemical characteristics of Prevotella species determined using these two systems are given in Supplementary Table S4 (available in IJSEM Online). Based on the results of API ZYM and API An-Ident, the six strains were divided into two groups, with one group consisting of five strains $\left(\mathrm{CB}^{\mathrm{T}}, \mathrm{CB} 18, \mathrm{CB} 23, \mathrm{CB} 26\right.$ and $\left.\mathrm{CB} 28\right)$ and one strain $\left(\mathrm{CB} 35^{\mathrm{T}}\right)$ in the other.

The $16 \mathrm{~S}$ rRNA gene sequences determined in this study were about 1500 bp long and phylogenetic analysis was based on about 1435 aligned homologous nucleotides (Escherichia coli positions 34-1482). The phylogenetic tree clearly indicated that the isolates were related to strains within the genus Prevotella (Fig. 1). Five strains $\left(\mathrm{CB}^{\mathrm{T}}{ }^{\mathrm{T}}, \mathrm{CB} 18\right.$, CB23, CB26 and CB28) formed a single cluster and a distinct line of descent; their sequence similarity to each other was 99.1-99.5\%. The 16S rRNA gene of $\mathrm{CB}^{\mathrm{T}}$ showed highest sequence similarity to that of $P$. veroralis JCM $6290^{\mathrm{T}}(92 \%)$. $\mathrm{CB} 35^{\mathrm{T}}$ formed a single cluster and a distinct line of descent. The 16S rRNA gene of $\mathrm{CB} 35^{\mathrm{T}}$ showed highest sequence similarity to that of $P$. shahii JCM $12083^{\mathrm{T}}(90 \%)$. These results indicated that strains $\mathrm{CB}^{\mathrm{T}}$ and $\mathrm{CB}^{\mathrm{T}}{ }^{\mathrm{T}}$ could 


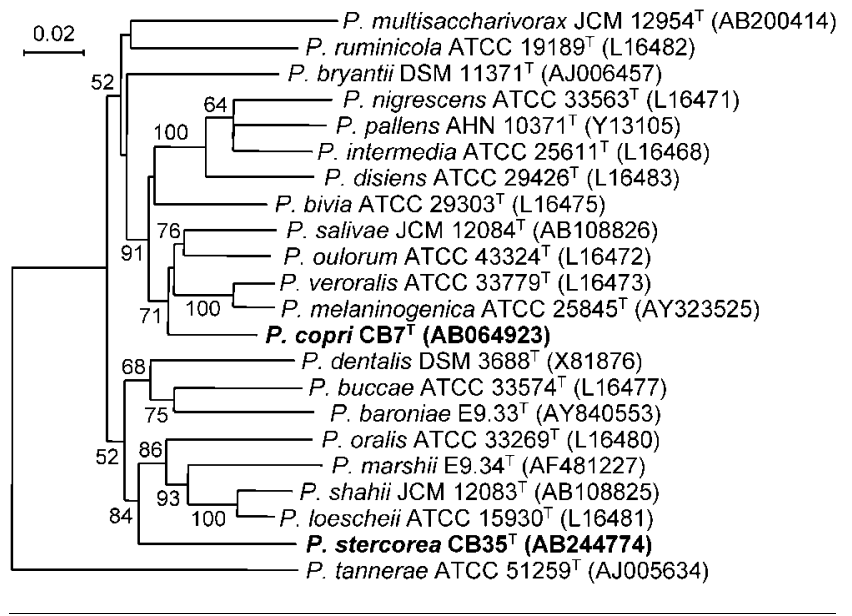

Fig. 1. Phylogenetic tree showing the relationship between strain $\mathrm{CB}^{\top}{ }^{\top}$ (Prevotella copri sp. nov.), strain $\mathrm{CB} 5^{\top}{ }^{\top}$ (Prevotella stercorea sp. nov.) and related Prevotella species. The tree was constructed by the neighbour-joining method based on $16 \mathrm{~S}$ rRNA gene sequences. Numbers at nodes indicate bootstrap values greater than $50 \%$. Bar, 0.02 substitutions per nucleotide position.

represent novel species, since $16 \mathrm{~S}$ rRNA gene sequence similarity to the most closely related species was $<97 \%$ (Stackebrandt \& Goebel, 1994). The DNA G + C contents of strains $\mathrm{CB}^{\mathrm{T}}, \mathrm{CB} 18, \mathrm{CB} 23, \mathrm{CB} 26$ and CB28 were $44.2-$ $45.9 \mathrm{~mol} \%$; that of strain $\mathrm{CB} 35^{\mathrm{T}}$ was $48.2 \mathrm{~mol} \%$.

Matsuki et al. (2004) analysed human gut microbiota (46 healthy adults) by real-time PCR using a Prevotella-specific primer. Prevotella was found in 21 of 46 subjects (46\%), with the $\log _{10}$ of the number of cells per $g$ wet weight being $9.7 \pm 0.8$. Some OTUs that belong to the genus Prevotella were also detected in 16S rRNA gene libraries (Eckburg et al., 2005; Hayashi et al., 2002a; Suau et al., 1999). These results suggest that members of the genus Prevotella are common in the human gut. The novel Prevotella species described here (represented by $\mathrm{CB}^{\mathrm{T}}$ and $\mathrm{CB} 35^{\mathrm{T}}$ ) were detected at high frequency using anaerobic culture-based methods (Hayashi et al., 2002a). These isolates represent two species that are important constituents of human gut microbiota.

On the basis of the results presented in this study, these strains could be classified as representatives of two novel species of the genus Prevotella. The names Prevotella copri sp. nov. and Prevotella stercorea sp. nov. are proposed for the five strains $\left(\mathrm{CB} 7^{\mathrm{T}}, \mathrm{CB} 18, \mathrm{CB} 23, \mathrm{CB} 26\right.$ and $\left.\mathrm{CB} 28\right)$ and for strain $\mathrm{CB}^{\mathrm{T}} 5^{\mathrm{T}}$, respectively. Differential characteristics of $P$. copri sp. nov., $P$. stercorea sp. nov. and some related Prevotella species are shown in Table 1.

\section{Description of Prevotella copri sp. nov.}

Prevotella copri (cop'ri. N.L. gen. n. copri from Gr. gen. n. kopron of/from faeces).
Cells are Gram-negative rods that are anaerobic and nonspore-forming. Colonies on EG agar plates after $48 \mathrm{~h}$ incubation at $37^{\circ} \mathrm{C}$ under $100 \% \mathrm{CO}_{2}$ are white, circular and convex. Optimum temperature for growth is $37^{\circ} \mathrm{C}$. Growth is inhibited on Bacteroides bile aesculin agar. Indolenegative and aesculin is hydrolysed. No activity is detected for urease and gelatin is not hydrolysed. Acid is produced from glucose, lactose, sucrose, maltose, raffinose, salicin, xylose, L-arabinose, cellobiose and L-rhamnose. Positive reactions are obtained using API ZYM for alkaline phosphatase, acid phosphatase, naphthol-AS-BI-phosphohydrolase, $\alpha$-galactosidase, $\beta$-galactosidase, $\alpha$-glucosidase and $\beta$-glucosidase; negative reactions are obtained for lipase (C4), leucine arylamidase, valine arylamidase, cystine arylamidase, trypsin, $\beta$-gluconidase, $N$-acetyl- $\beta$-D-glucosaminidase, $\alpha$-mannosidase and $\alpha$-fucosidase. Positive reactions are obtained using An-Ident for $\alpha$-glucosidase, $\alpha$-arabinofuranosidase, $\beta$-gluconidase, alkaline phosphatase, $\alpha$-galactosidase, indoxylacetate hydrolase and arginine and alanine aminopeptidases; negative reactions are obtained for indole, $N$-acetyl- $\beta$-D-glucosaminidase, $\alpha$-L-fucosidase, $\beta$-galactosidase, pyroglutamic acid arylamidase, leucine, proline, tyrosine, arginine, histidine, phenylalanine and glycine aminopeptidases and catalase. The major metabolic end products are succinic and acetic acids. Major fatty acids are $\mathrm{C}_{16: 0}(12-13 \%), \mathrm{C}_{18: 1} \omega 9 c(13-18 \%)$ and anteiso- $\mathrm{C}_{15: 0}$ (20-27\%). The principal respiratory quinones are menaquinones MK-10 (8-10\%), MK-11 (23-26\%), MK-12 (43-45\%) and MK-13 (15-19\%). Minor menaquinones are MK-8 (0-1\%) and MK-9 (1-4\%).

The type strain is $\mathrm{CB}^{\mathrm{T}}\left(=\mathrm{JCM} 13464^{\mathrm{T}}=\mathrm{DSM} 18205^{\mathrm{T}}\right)$, isolated from human faeces. Strains CB18 (= JCM 13465), CB23 (=JCM 13466), CB26 (=JCM 13467) and CB28 ( = JCM 13468) are included in this species. The DNA G $+\mathrm{C}$ contents of the five known strains are 44.2-45.9 mol\%.

\section{Description of Prevotella stercorea sp. nov.}

Prevotella stercorea (ster.co're.a. L. fem. adj. stercorea pertaining to faeces).

Cells are Gram-negative rods that are anaerobic and nonspore-forming. Colonies on EG agar plates after $48 \mathrm{~h}$ incubation at $37{ }^{\circ} \mathrm{C}$ under $100 \% \mathrm{CO}_{2}$ gas are translucent, circular, entire, slightly convex and smooth. Optimum temperature for growth is $37^{\circ} \mathrm{C}$. Growth is inhibited on Bacteroides bile aesculin agar. Negative for indole, does not hydrolyse aesculin or gelatin and no urease activity is detected. Acid is produced from glucose, lactose, sucrose, maltose, mannose and raffinose. Positive reactions are obtained using API ZYM for alkaline phosphatase, acid phosphatase, naphthol-AS-BI-phosphohydrolase, $\beta$-galactosidase, $\alpha$-glucosidase, $N$-acetyl- $\beta$-glucosaminidase and $\alpha$ L-fucosidase; negative reactions are obtained for esterase (C4), esterase lipase (C8), lipase (C4), leucine arylamidase, valine arylamidase, cystine arylamidase, trypsin, chymotrypsin, $\beta$-gluconidase and $\beta$-glucosidase. Positive reactions are obtained using An-Ident for $N$-acetyl- $\beta$-D-glucosaminidase, 
Table 1. Differential characteristics of Prevotella copri sp. nov., Prevotella stercorea sp. nov. and related Prevotella type strains

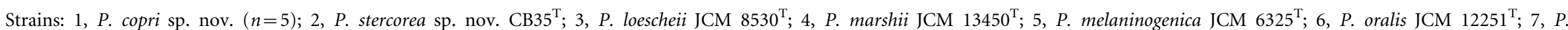

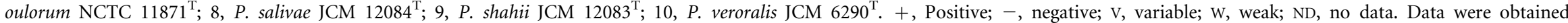
in this study unless indicated otherwise with the exception of P. oulorum NCTC $11871^{\mathrm{T}}$ (data from Shah et al., 1985).

\begin{tabular}{|c|c|c|c|c|c|c|c|c|c|c|}
\hline Characteristic & 1 & 2 & 3 & 4 & 5 & 6 & 7 & 8 & 9 & 10 \\
\hline Aesculin hydrolysis & + & - & + & - & - & + & + & + & - & + \\
\hline \multicolumn{11}{|l|}{ Acid production from: } \\
\hline Lactose & + & + & + & - & + & + & + & + & + & + \\
\hline Sucrose & + & + & + & - & + & + & + & + & + & + \\
\hline Salicin & + & - & - & - & - & - & - & + & - & - \\
\hline D-Xylose & + & - & - & - & - & - & - & + & - & - \\
\hline L-Arabinose & + & - & - & - & - & - & - & + & - & - \\
\hline Gelatin & - & - & + & + & + & - & - & - & + & - \\
\hline D-Cellobiose & + & - & - & - & - & + & - & + & - & + \\
\hline D-Mannose & - & + & + & + & + & + & + & + & + & + \\
\hline D-Melezitose & $\mathrm{V}$ & - & - & - & - & - & - & - & - & - \\
\hline L-Rhamnose & + & - & - & - & - & - & - & - & - & - \\
\hline \multicolumn{11}{|l|}{ Enzyme activities: } \\
\hline Esterase lipase (C8) & $\mathrm{W}$ & - & - & - & - & - & $\mathrm{ND}$ & - & - & - \\
\hline Chymotrypsin & $\mathrm{W}$ & - & - & $\mathrm{W}$ & - & $\mathrm{w}$ & $\mathrm{ND}$ & - & - & - \\
\hline$\beta$-Glucosidase & + & - & $\mathrm{V}$ & - & - & $\mathrm{w}$ & ND & + & - & - \\
\hline$\alpha$-Mannosidase & - & $\mathrm{W}$ & - & - & - & $\mathrm{w}$ & ND & - & - & - \\
\hline$N$-Acetyl- $\beta$-D-glucosaminidase & - & + & + & - & + & + & ND & + & + & + \\
\hline$\alpha$-Arabinofuranosidase & + & - & - & - & - & - & $\mathrm{ND}$ & + & - & - \\
\hline$\alpha$-L-Fucosidase & - & + & + & - & + & + & $\mathrm{ND}$ & + & + & + \\
\hline$\alpha$-Galactosidase & + & + & + & - & + & + & $\mathrm{ND}$ & $\mathrm{W}$ & $\mathrm{w}$ & $\mathrm{w}$ \\
\hline$\beta$-Galactosidase & - & - & + & - & + & $\mathrm{W}$ & $\mathrm{ND}$ & + & $\mathrm{W}$ & + \\
\hline Pyroglutamic acid arylamidase & - & - & - & + & - & - & $\mathrm{ND}$ & - & - & - \\
\hline Arginine aminopeptidase & - & - & + & - & + & - & ND & - & - & - \\
\hline Histidine aminopeptidase & - & - & - & - & + & - & ND & - & - & - \\
\hline Major cellular fatty acids & $\begin{array}{c}\mathrm{C}_{16: 0} \\
\mathrm{C}_{18: 1} \omega 9 c \\
\text { anteiso- } \mathrm{C}_{15: 0}\end{array}$ & $\begin{array}{l}\mathrm{C}_{18: 1} \omega 9 c \\
\text { iso- } \mathrm{C}_{15: 0} \\
\text { anteiso- } \mathrm{C}_{15: 0}\end{array}$ & $\begin{array}{c}\mathrm{C}_{16: 0} \\
\mathrm{C}_{18: 1} \omega 9 c \\
\text { anteiso- } \mathrm{C}_{15: 0}\end{array}$ & $\begin{array}{c}\mathrm{C}_{18: 1} \omega 9 c \\
\text { anteiso- } \mathrm{C}_{15: 0}\end{array}$ & $\begin{array}{c}\mathrm{C}_{18: 1} \omega 9 c \\
\text { anteiso- } \mathrm{C}_{15: 0}\end{array}$ & $\begin{array}{c}\mathrm{C}_{16: 0}, \mathrm{C}_{18: 1} \omega 9 c \\
\mathrm{C}_{16: 0} 3-\mathrm{OH} \\
\text { anteiso- } \mathrm{C}_{15: 0}\end{array}$ & $\begin{array}{l}\text { iso- } \mathrm{C}_{15: 0} \\
\text { anteiso- } \mathrm{C}_{15: 0} \\
\text { iso- } \mathrm{C}_{17: 0}\end{array}$ & $\begin{array}{c}\mathrm{C}_{18: 1} \omega 9 c \\
\text { iso- } \mathrm{C}_{17: 0} \\
3-\mathrm{OH}, \\
\text { anteiso- } \mathrm{C}_{15: 0}\end{array}$ & $\begin{array}{c}\mathrm{C}_{13: 0}, \mathrm{C}_{16: 0} \\
\mathrm{C}_{18: 1} \omega 9 c \\
\mathrm{C}_{16: 0} 3-\mathrm{OH}\end{array}$ & $\begin{array}{c}\mathrm{C}_{18: 1} \omega 9 c \\
\text { anteiso- } \mathrm{C}_{15: 0}\end{array}$ \\
\hline Predominant menaquinone(s) & $11,12,13$ & 12,13 & $10^{a_{\star}}$ & 11,12 & $10,11^{a}$ & 13 & 10,11 & $11,12^{a}$ & $10,11,12^{a}$ & $10,11^{a}$ \\
\hline DNA G $+\mathrm{C}$ content $(\mathrm{mol} \%)$ & $44.2-45.9$ & 48.2 & 46.9 & $51^{b}$ & $41.1^{a}$ & $43.1^{c}$ & 45.1 & 41.3 & 44.3 & $42.1^{c}$ \\
\hline
\end{tabular}

${ }^{\star}$ Data from other studies as follows: a, Sakamoto et al. (2004); b, Downes et al. (2005); c, Watabe et al. (1983). 
$\alpha$-glucosidase, $\alpha$-L-fucosidase, alkaline phosphatase, $\alpha$-galactosidase, indoxylacetate hydrolase and alanine aminopeptidase; negative reactions are obtained for indole, $\alpha$-arabinofuranosidase, $\beta$-gluconidase, $\beta$-galactosidase, $\mathrm{pyr}$ oglutamic acid arylamidase, arginine, leucine, proline, tyrosine, histidine, phenylalanine and glycine aminopeptidases and catalase. The major metabolic end products are succinic and acetic acids; small amounts of iso-valeric acid are also produced. Major fatty acids are $\mathrm{C}_{18: 1} \omega 9 c(15 \%)$, iso- $\mathrm{C}_{15: 0}(24 \%)$ and anteiso- $\mathrm{C}_{15: 0}(26 \%)$. The principal respiratory quinones are menaquinones MK-12 (26\%) and MK-13 (50\%); minor menaquinones are MK-9 (1\%), MK-10 (5\%) and MK-11 (7\%).

The type strain is $\mathrm{CB}^{2} 5^{\mathrm{T}}\left(=\mathrm{JCM} 13469^{\mathrm{T}}=\mathrm{DSM} 18206^{\mathrm{T}}\right)$, isolated from human faeces. The DNA G $+\mathrm{C}$ content of the type strain is $48.2 \mathrm{~mol} \%$.

\section{Acknowledgements}

We are grateful to Professor Dr H. G. Trüper, University of Bonn, Germany, for his suggestions regarding nomenclature. We thank Dr S. Karita, Mie University, Japan, for help in DNA extraction techniques.

\section{References}

Downes, J., Sutcliffe, I., Tanner, A. C. R. \& Wade, W. G. (2005). Prevotella marshii sp. nov. and Prevotella baroniae sp. nov., isolated from the human oral cavity. Int J Syst Evol Microbiol 55, 1551-1555.

Eckburg, P. B., Bik, E. M., Bernstein, C. N., Purdom, E., Dethlefsen, L., Sargent, M., Gill, S. R., Nelson, K. E. \& Relman, D. A. (2005). Diversity of the human intestinal microbial flora. Science 308, 16351638.

Felsenstein, J. (1985). Confidence limits on phylogenies: an approach using the bootstrap. Evolution 39, 783-791.

Hayashi, H., Sakamoto, M. \& Benno, Y. (2002a). Phylogenetic analysis of the human gut microbiota using $16 \mathrm{~S}$ rDNA clone libraries and strictly anaerobic culture-based methods. Microbiol Immunol 46, 535-548.

Hayashi, H., Sakamoto, M. \& Benno, Y. (2002b). Fecal microbial diversity in a strict vegetarian as determined by molecular analysis and cultivation. Microbiol Immunol 46, 819-831.

Hold, G. L., Pryde, S. E., Russell, V. J., Furrie, E. \& Flint, H. J. (2002). Assessment of microbial diversity in human colonic samples by $16 \mathrm{~S}$ rDNA sequence analysis. FEMS Microbiol Ecol 39, 33-39.

Holdeman, L. V., Cato, E. P. \& Moore, W. E. C. (1977). Anaerobe Laboratory Manual, 4th edn. Blacksburg, VA: Virginia Polytechnic Institute and State University.

Kimura, M. (1980). A simple method for estimating evolutionary rates of base substitutions through comparative studies of nucleotide sequences. J Mol Evol 16, 111-120.

Kitahara, M., Takamine, F., Imamura, T. \& Benno, Y. (2001). Clostridium hiranonis sp. nov., a human intestinal bacterium with bile acid $7 \alpha$-dehydroxylating activity. Int J Syst Evol Microbiol 51, 39-44.

Komagata, K. \& Suzuki, K. (1987). Lipid and cell-wall analysis in bacterial systematics. Methods Microbiol 19, 161-207.

Laughon, B. E., Syed, S. A. \& Loesche, W. J. (1982). API ZYM system for identification of Bacteroides spp., Capnocytophaga spp., and spirochetes of oral origin. J Clin Microbiol 15, 97-102.
Matsuki, T., Watanabe, K., Fujimoto, J., Takada, T. \& Tanaka, R. (2004). Use of $16 \mathrm{~S}$ rRNA gene-targeted group-specific primers for real-time PCR analysis of predominant bacteria in human feces. Appl Environ Microbiol 70, 7220-7228.

Mayberry, W. R., Lambe, D. W., Jr \& Ferguson, K. P. (1982). Identification of Bacteroides species by cellular fatty acid profiles. Int J Syst Bacteriol 32, 21-27.

Mitsuoka, T., Morishita, Y., Terada, A. \& Yamamoto, S. (1969). A simple method ('plate-in-bottle method') for the cultivation of fastidious anaerobes. Jpn J Microbiol 13, 383-385.

Miyagawa, E., Azuma, R. \& Suto, T. (1979). Cellular fatty acid composition in gram-negative obligately anaerobic rods. J Gen Appl Microbiol 25, 41-51.

Saitou, N. \& Nei, M. (1987). The neighbor-joining method: a new method for reconstructing phylogenetic trees. Mol Biol Evol 4, 406-425.

Sakamoto, M., Suzuki, M., Umeda, M., Ishikawa, I. \& Benno, Y. (2002). Reclassification of Bacteroides forsythus (Tanner et al. 1986) as Tannerella forsythensis corrig., gen. nov., comb. nov. Int J Syst Evol Microbiol 52, 841-849.

Sakamoto, M., Suzuki, M., Huang, Y., Umeda, M., Ishikawa, I. \& Benno, Y. (2004). Prevotella shahii sp. nov. and Prevotella salivae sp. nov., isolated from the human oral cavity. Int J Syst Evol Microbiol 54, 877-883.

Sakamoto, M., Huang, Y., Umeda, M., Ishikawa, I. \& Benno, Y. (2005a). Prevotella multiformis sp. nov., isolated from human subgingival plaque. Int J Syst Evol Microbiol 55, 815-819.

Sakamoto, M., Umeda, M., Ishikawa, I. \& Benno, Y. (2005b). Prevotella multisaccharivorax sp. nov., isolated from human subgingival plaque. Int J Syst Evol Microbiol 55, 1839-1843.

Sakka, K., Furuse, S. \& Shimada, K. (1989). Cloning and expression in Escherichia coli of thermophilic Clostridium sp. F1 gene related to cellulose hydrolysis. Agric Biol Chem 53, 905-910.

Shah, H. N. (1992). The genus Bacteroides and related taxa. In The Prokaryotes, 2nd edn, pp. 3593-3607. Edited by A. Balows, H. G. Trüper, M. Dworkin, W. Harder \& K. H. Schleifer. New York: Springer.

Shah, H. N. \& Collins, M. D. (1980). Fatty acid and isoprenoid quinone composition in the classification of Bacteroides melaninogenicus and related taxa. J Appl Bacteriol 48, 75-87.

Shah, H. N. \& Collins, M. D. (1983). Genus Bacteroides. A chemotaxonomical perspective. J Appl Bacteriol 55, 403-416.

Shah, H. N., Collins, M. D., Watabe, J. \& Mitsuoka, T. (1985). Bacteroides oulorum sp. nov., a nonpigmented saccharolytic species from the oral cavity. Int J Syst Bacteriol 35, 193-197.

Slots, J. (1981). Enzymatic characterization of some oral and nonoral gram-negative bacteria with the API ZYM system. J Clin Microbiol 14, 288-294.

Stackebrandt, E. \& Goebel, B. M. (1994). Taxonomic note: a place for DNA-DNA reassociation and 16S rRNA sequence analysis in the present species definition in bacteriology. Int J Syst Bacteriol 44, 846-849.

Suau, A., Bonnet, R., Sutren, M., Godon, J.-J., Gibson, G. R., Collins, M. D. \& Doré, J. (1999). Direct analysis of genes encoding $16 \mathrm{~S}$ rRNA from complex communities reveals many novel molecular species within the human gut. Appl Environ Microbiol 65, 4799-4807.

Tamaoka, J. \& Komagata, K. (1984). Determination of DNA base composition by reversed-phase high-performance liquid chromatography. FEMS Microbiol Lett 25, 125-128.

Tanner, A. C. R., Strzempko, M. N., Belsky, C. A. \& McKinley, G. A. (1985). API ZYM and API An-Ident reactions of fastidious oral gram-negative species. J Clin Microbiol 22, 333-335. 
Thompson, J. D., Higgins, D. G. \& Gibson, T. J. (1994). CLUSTAL W: improving the sensitivity of progressive multiple sequence alignment through sequence weighting, position-specific gap penalties and weight matrix choice. Nucleic Acids Res 22, 4673-4680.

Watabe, J., Benno, Y. \& Mitsuoka, T. (1983). Taxonomic study of Bacteroides oralis and related organisms and proposal of Bacteroides veroralis sp. nov. Int J Syst Bacteriol 33, 57-64.
Wilson, K. H. \& Blitchington, R. B. (1996). Human colonic biota studied by ribosomal DNA sequence analysis. Appl Environ Microbiol 62, 2273-2278.

Zoetendal, E. G., Akkermans, A. D. \& de Vos, W. M. (1998). Temperature gradient gel electrophoresis analysis of $16 \mathrm{~S}$ rRNA from human fecal samples reveals stable and host-specific communities of active bacteria. Appl Environ Microbiol 64, 3854-3859. 